\title{
Top 15 Tips on Becoming an Effective Medical Simulation Performer/Writer/ Director
}

Xiao C Zhang ${ }^{1 *}$, Scott Pasichow ${ }^{1}$, Melissa Bowler ${ }^{2}$ and David Lindquist ${ }^{3}$

${ }^{1}$ Alpert Medical School of Brown University, Emergency Medicine Residency, Providence, RI, USA

${ }^{2}$ Providence Improv Guild, Providence, RI, USA

${ }^{3}$ Alpert Medical School of Brown University, Department of Emergency Medicine, Providence, RI,USA

"Corresponding author: Xiao C Zhang, Alpert Medical School of Brown University, Emergency Medicine Residency, Providence, RI, USA, Tel: +1401-863-1000; E-mail: xzhang09@gmail.com

Rec date: July 10, 2016; Acc date: July 18, 2016; Pub date: July 24, 2016

Copyright: (c) 2016 Zhang XC, et al. This is an open-access article distributed under the terms of the Creative Commons Attribution License, which permits unrestricted use, distribution, and reproduction in any medium, provided the original author and source are credited.

\section{Letter to Editor}

Medical simulation has become an important platform for medical education by allowing learners to be exposed to rare but challenging clinical and social situations in a targeted, simulated learning environment. While high-fidelity simulation incorporates advanced programming software with life-like manikins that can blink, sweat, or even bleed, technology's ability to replicate real-time human interactions remains limited. The use of human actors/standardized patients can add significant constructive tension and realism to a case, and permits exploration of complex patient-provider dynamics.

An engaging simulation case challenges the participants clinically, creates moments of unavoidable decision-making, offers a pathway to resolution yet accommodates the range of possible participant responses. This requires the collaboration of the case creator and confederates to clarify the learning objectives and plan for anticipated participant actions. Strong improvisational actors respond well to defined endpoints by giving actors extra room to apply their acting skills toward the learning objective (e.g. "continue to ask questions, appearing anxious and confused until the doctor explains the risks of thrombolytic in lay terms"). At times, however, junior educators and residents may be asked to play a confederate. Although well trained clinically, resident confederates can feel unprepared, vulnerable, and insecure about stepping into this role. These feelings may be amplified when their peers are the scenario participants.

To understand the requirements of the acting roles, we interviewed $\mathrm{MB}$, a professional actor and expert standardized patient for her "Top 5 Do's and Don'ts of a Successful Simulation Actor" and her "Top 5 Suggestions for a Successful Simulation Case-Writer” (Tables 1-3).

\begin{tabular}{|c|c|}
\hline \multicolumn{2}{|c|}{ Top 5 “Do's” for a Successful Simulation Actor } \\
\hline “Do” Tips & Actor's Feedback \\
\hline Be Professional & $\begin{array}{l}\text { It is important for you to stay in character throughout the entire case to promote believability and encourage your } \\
\text { learners to take you seriously. Be professional - Acting is harder than it looks and staying in character while your } \\
\text { body is being examined can be very challenging. Take the case seriously and remember that a real patient } \\
\text { doesn't think the details of their symptoms are funny so avoid giggling }\end{array}$ \\
\hline Pull from real-life experiences & $\begin{array}{l}\text { While you may never have suffered from appendicitis, myocardial infarction, or inebriation, chances are, you have } \\
\text { provided care for patients with these complaints. By drawing from your personal clinical experiences, you are able } \\
\text { to reproduce a much more believable character performance throughout the simulation }\end{array}$ \\
\hline Be empathetic & $\begin{array}{l}\text { In order to convince the learners of your confederate role, it is helpful to appreciate and understand the character } \\
\text { that you are portraying by placing yourself in their situation. Imagine how you would feel if you had suddenly } \\
\text { developed crushing chest pain after climbing a flight of stairs; channel your inner empathy and allow it to fuel your } \\
\text { performance }\end{array}$ \\
\hline Allow for pauses & $\begin{array}{l}\text { Not every awkward silence needs to be filled up with dialogue. Allow the learners to process the barrage of } \\
\text { information needed for them to assess the clinical situation; you can take this time to readjust and focus on your } \\
\text { role and prepare to guide your learners to the next objective. Sometimes } 8-10 \text { seconds of silence is needed for } \\
\text { processing, don't feel the need to fill that time with noise }\end{array}$ \\
\hline Practice.... lot & $\begin{array}{l}\text { As obvious as this may sound, practicing your role before the actual simulation case with real-time feedback is } \\
\text { incredibly helpful and highly recommended }\end{array}$ \\
\hline
\end{tabular}

Table 1: Top 5 "Do's" for a successful simulation actor.

Actor's Bios: Melissa Bowler (MB) is the Executive Director of the Providence Improv Guild and has been performing professionally since 2005. She is a simulation specialist at Women and Infants
Hospital and a Standardized Patient at Alpert Warren Medical School at Brown University. She lives in Providence, Rhode Island with her three-year-old son, Luc. 
Citation: Zhang XC, Pasichow S, Bowler M, Lindquist D (2016) Top 15 Tips on Becoming an Effective Medical Simulation Performer/Writer/ Director. Gen Med (Los Angeles) 4: 262. doi:10.4172/2327-5146.1000262

Page 2 of 2

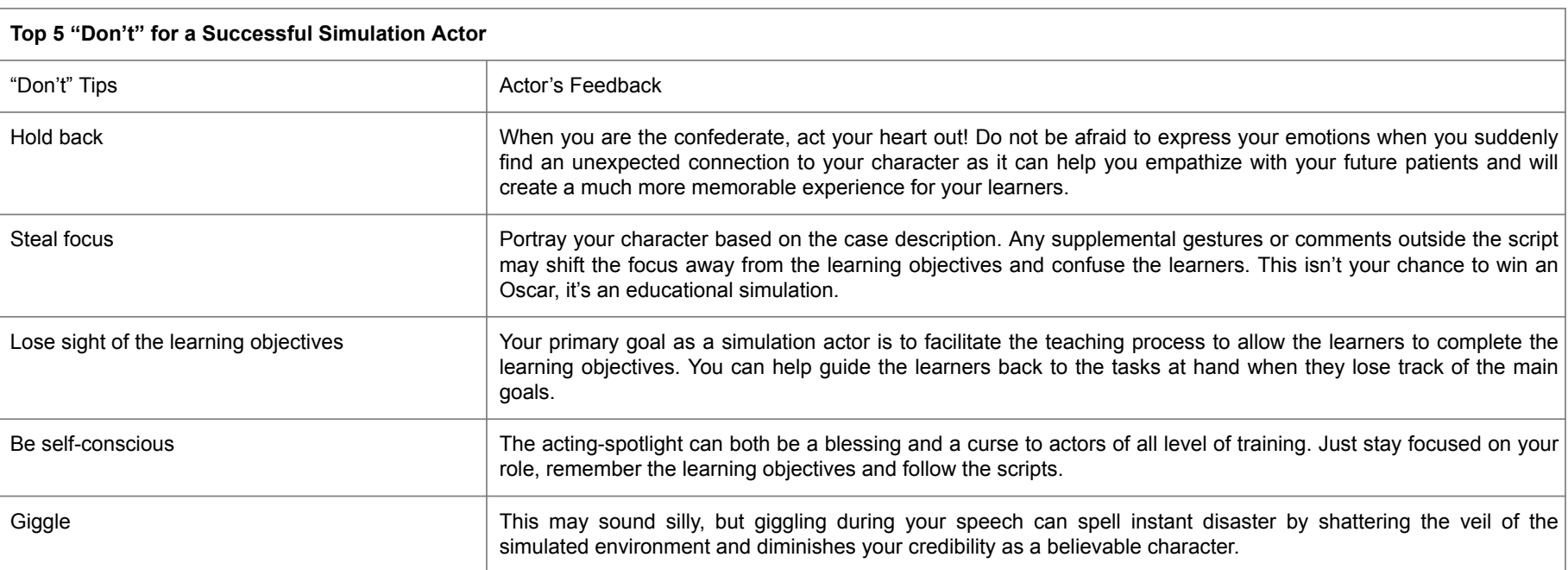

Table 2: Top 5 "Don't" for a successful simulation actor.

\begin{tabular}{|c|c|}
\hline \multicolumn{2}{|c|}{$\begin{array}{l}\text { Top } 5 \text { Suggestions for a Successful Simulation Case-Writer } \\
\text { (From an actor's perspective) }\end{array}$} \\
\hline Suggestions & Actor's Feedback \\
\hline Provide a detailed case information & $\begin{array}{l}\text { Providing detailed descriptions of the scenario, patient background (both social and medical) and specific } \\
\text { emotional responses can be incredibly helpful for the actor as it provides a transparent snapshot into the mind of } \\
\text { the case writer on what is expected from the actor and obviates the need for anxiety provoking improvisation. }\end{array}$ \\
\hline Keep the case simple & $\begin{array}{l}\text { A simple case with clear and concise learning objectives, along with easy-to-follow acting queues allows the actor } \\
\text { and learners to focus on the key case elements and leaves little room for unexpected behaviors or complicated } \\
\text { and divergent decision pathways. }\end{array}$ \\
\hline Expected the unexpected & $\begin{array}{l}\text { Sometimes learners may not choose the clinical decision pathway that you had envisioned. It is helpful anticipate } \\
\text { all potential deviation from the intended pathway and provide your confederates with a scripted response to guide } \\
\text { the learners back on track. }\end{array}$ \\
\hline Allow for active feedback & $\begin{array}{l}\text { Direct feedback after a simulation session is mutually beneficial for both the learners and the actors. You should } \\
\text { allow enough time to review the learning goals, gauge the overall reaction to your case, as well as allowing the } \\
\text { students and confederates to provide constructive criticisms on both the case design and actor performance to } \\
\text { make it even better during future iterations. }\end{array}$ \\
\hline Be transparent & $\begin{array}{l}\text { Your case, along with the learning objectives and character bios should be discussed with the entire team, } \\
\text { including the programmers, actors and introductory. Adding a secret plot twist at the last minute can ruin an entire } \\
\text { case. }\end{array}$ \\
\hline
\end{tabular}

Table 3: Top 5 suggestions for a successful simulation case-writer.

\section{Final Thoughts}

"Don't give up!" No one is perfect at following these tips, writing Shakespearian cases, or winning their Oscars during their first audition. We recommend that writers and actors reflect on your performance and your case, gather feedback, and practice; you will get better with each repetition. We hope these 15 tips have sparked an interest in and quelled a few fears about providing a memorable teaching experience for your learners, your peers, and yourself. 